\title{
Analisis Citra Simulator Unit Radiologi RSUD dr. Moewardi Surakarta
}

\author{
Zening Damaringtyas, ${ }^{*}$ Mohtar Yunianto, dan Harjana \\ Laboratorium Komputasi Jurusan Fisika, \\ FMIPA-Universitas Sebelas Maret \\ Jl. Ir. Sutami No 36A Surakarta 57126
}

\begin{abstract}
Intisari
Telah dilaksanakan penelitian tentang analisis citra simulator unit radiologi RSUD dr. Moewardi Surakarta. Citra yang dihasilkan simulator sebagai verifikasi lapangan dalam radioterapi. Citra tersebut akan ditajamkan sehingga batasan luas lapangan semakin jelas. Citra diolah dengan metode deteksi tepi yang telah diprogram melalui perangkat lunak Matlab. Tampilan program berupa GUI (Graphic User Interface) sehingga mudah digunakan. Selain metode deteksi tepi, program juga melakukan perhitungan aksis lapangan penyinaran. Perhitungan aksis lapangan penyinaran berdasarkan informasi yang diperoleh pada citra meliputi faktor magnifikasi dan axis penyinaran. Hasil dari penelitian ini adalah suatu program yang dapat mendeteksi tepi citra secara tepat dan sesuai gambar asli dan dapat menghitung besarnya aksis lapangan penyinaran secara teliti.
\end{abstract}

\begin{abstract}
The research has been conducted about simulator's image analysis on the radiology unit at the Hospital of dr. Moewardi Surakarta. The image result of the simulator as a verification in radiotherapy. The image is sharpened so that restrictions wide field increasingly clear. The image processed by using edge detection that have been programmed through software MATLAB. Program appearance form of GUI (Graphic User Interface) so it is easy to use. In addition to edge detection methods, the program also conduct the calculations of irradiation field. The irradiation field calculations based upon information obtained on the image covers the magnification factor and axis irradiation. The result of this research is a program that can detect edge of image accurately according to the original image and calculate the irradiation field thoroughly.
\end{abstract}

KATA KUNCI: Image, Simulator, Edge Detection, Irradiation Field

\section{PENDAHULUAN}

Radioterapi memanfaatkan radiasi dari sumber radioaktif untuk mematikan sel-sel kanker dalam tubuh dengan dosis tertentu. Radioterapi ada 2 macam, yakni teleterapi dan brachyterapi. Langkah awal dalam radioterapi yaitu simulasi. Simulasi menggunakan alat simulator yang didesain hampir mirip dengan alat teleterapi. Simulasi menggunakan pencitraan Sinar-X secara fluoroskopi, seolah-olah sedang melakukan treatment penyinaran dengan pesawat radioterapi. Perbedaan simulator dan alat radioterapi adalah sumber yang digunakan. Simulator menggunakan sinar-X, teleterapi menggunakan sumber radioaktif Co-60 untuk mendapatkan radiasi sinar gamma.

Simulator memanfaatkan sifat-sifat sinar-X meliputi, daya tembus terhadap materi, penyerapan sinar-X oleh suatu materi yang dikenai, efek fotografi, luminisensi daya peterbaran

*E-MAIL: brigittazening@gmail.com dan ionisasi [1]. Simulator menghasilkan citra sinar-X (foto Roentgen) yang berisi informasi tentang verifikasi lapangan. Citra yang diambil adalah citra letak kanker pada pasien, sehingga dari citra simulator tersebut didapat informasi tentang organ mana saja yang harus dilindungi ketika dilakukan teleterapi. Sifat-sifat sinar-X dan proses pencetakan menyebabkan citra sinar-X yang dihasilkan terdapat derau sehingga citra menjadi tidak jelas. Penajaman citra simulator akan membantu ketelitian tempat dan perhitungan aksis lapangan.

Citra simulator harus melalui proses digitalisasi, sehingga dapat diolah menggunakan perangkat komputer. Terdapat aspek-aspek dalam pengolahan cinta, antara lain: meningkatkan kualitas informasi dalam citra untuk kepentingan interpretasi dan untuk mempermudah pemrosesan guna pengambilan keputusan [2]. Penajaman citra menggunakan metode deteksi tepi. Metode deteksi tepi akan mendeteksi tepian citra dengan kernel. Kernel merupakan matriks yang berisi bilangan-bilangan dengan ukuran matriks yang kecil pada umumnya berukuran $2 \times 2$ atau $3 \times 3$. Kernel digunakan dalam proses konvolusi citra, sehingga kernel bergerak melalui semua elemen citra secara teratur [3]. 


\begin{tabular}{|l|l|}
\hline$X-$ & $Y+$ \\
\hline & $X+$ \\
\hline & $Y-$ \\
\hline
\end{tabular}

Gambar 1: Grid aksis penyinaran.

TABEL I: Kernel Sobel Vertikal $\left(\mathrm{S}_{x}\right)$.

\begin{tabular}{|r|l|l|}
\hline-1 & 0 & 1 \\
\hline 2 & 0 & 2 \\
\hline-1 & 0 & 1 \\
\hline
\end{tabular}

\section{METODOLOGI PENELITIAN}

\section{Magnifikasi Citra Simulator}

Citra simulator diambil melalui control simulator dengan mengatur jarak obyek ke film, akan diperoleh besarnya faktor magnifikasi citra:

$$
M=\frac{D_{1}+D_{2}}{D_{1}}
$$

dengan $\mathrm{M}=$ magnifikasi/skala perbesaran, $\mathrm{D}_{1}=$ jarak penyinaran dari sumber terhadap obyek $(\mathrm{cm}), \mathrm{D}_{2}=$ jarak obyek dengan film (cm).

\section{Aksis lapangan penyinaran}

Aksis lapangan penyinaran tergambar berupa grid yang tergambar pada citra simulator. Grid tersebut menggambarkan axis-axis penyinaran. Axis tersebut diberi nama $\mathrm{x}^{+}$, $\mathrm{x}^{-}, \mathrm{y}^{+}, \mathrm{y}^{-}$(Gambar 1).

Aksis penyinaran yang sebenarnya dipengaruhi oleh faktor magnifikasi, karena luasan tersebut dihitung dari citra simulator:

$$
\begin{aligned}
X_{ \pm \text {sebenarnya }} & =M \times X_{ \pm \text {pada film }} \\
Y_{ \pm \text {sebenarnya }} & =M \times Y_{ \pm \text {pada film }}
\end{aligned}
$$

\section{Deteksi Tepi}

Konsep dasar deteksi tepi yaitu perbedaan nilai suatu elemen dengan nilai elemen tetangganya. Digunakan beberapa metode deteksi tepi, yakni:

1. Metode Sobel

Susunan pixel $[i, j]$ untuk operator Sobel diperlihatkan pada Tabel I dan Tabel II.

Magnitude gradient dihitung dengan persamaan:

$$
M=\sqrt{S_{x}^{2}+S_{y}^{2}}
$$

TABEL II: Kernel Sobel Horisontal $\left(\mathrm{S}_{y}\right)$.

\begin{tabular}{|c|c|c|}
\hline-1 & -2 & 1 \\
\hline 0 & 0 & 0 \\
\hline 1 & 2 & 1 \\
\hline
\end{tabular}

TABEL III: Kernel Roberts Vertikal $\left(\mathrm{G}_{x}\right)$.

$$
\begin{array}{|l|l|}
\hline 1 & 0 \\
\hline 0 & -1 \\
\hline
\end{array}
$$

Turunan parsialnya:

$$
\begin{aligned}
& S_{x}=\left(a_{2}+c a_{3}+a_{4}\right)-\left(a_{0}+c a_{1}+a_{6}\right) \\
& S_{y}=\left(a_{0}+c a_{1}+a_{2}\right)-\left(a_{6}+c a_{5}+a_{4}\right)
\end{aligned}
$$

Konstanta $\mathrm{c}=2$.

\section{Metode Roberts}

Metode Roberts menggunakan operator dengan pendekatan yang sederhana dengan tingkat komputasi yang cepat. Penghitungan magnitude gradient menggunakan persamaan:

$$
G[f[i, j]]=\left|G_{x}\right|+\left|G_{y}\right|
$$

$\mathrm{G}_{x}$ dan $\mathrm{G}_{y}$ dihitung dengan kernel seperti ditunjukkan pada Tabel 3 dan Tabel 4 .

3. Metode Prewitt

Operator Prewitt merupakan kebalikan operator Sobel. Operator Prewitt menggunakan kernel seperti ditunjukkan Tabel 5 dan tabel 6 .

\section{Metode LoG}

Kombinasi dari filter Gaussian dan detektor tepi Laplacian. Pada metode LoG, filter Gaussian digunakan untuk memperhalus obyek, sedangkan turunan keduanya digunakan untuk mencari batasan obyek.

Derau yang terdapat pada obyek akan dikurangi dengan mengkonvolusikan citra obyek dengan filter Gaussian. Konvolusi dari operator LoG dinyatakan dalam h(x,y):

$$
\begin{aligned}
h(x, y) & =\Delta^{2}\left[g(x, y)^{*} f(x, y)\right] \\
& =\left[\Delta^{2} g(x, y)\right]^{*} f(x, y)
\end{aligned}
$$

dengan

$$
\Delta^{2} g(x, y)=\left(\frac{x^{2}+y^{2}-2 \sigma^{2}}{\sigma^{4}}\right)^{-\left(x^{2}+y^{2}\right) / 2 \sigma^{2}}
$$

\section{Metode Canny}

Metode Canny menggunakan pendekatan operator yang

TABEL IV: Kernel Roberts Horisontal $\left(\mathrm{G}_{y}\right)$.

$$
\begin{array}{|l|c|}
\hline 0 & -1 \\
\hline 1 & 0 \\
\hline
\end{array}
$$


TABEL V: Kernel Prewitt Vertikal $\left(\mathrm{S}_{x}\right)$.

\begin{tabular}{|c|c|c|}
\hline-1 & -1 & -1 \\
\hline 0 & 0 & 0 \\
\hline 1 & 0 & 1 \\
\hline
\end{tabular}

TABEL VI: Kernel Prewitt Horisontal $\left(\mathrm{S}_{y}\right)$.

\begin{tabular}{|c|c|c|}
\hline-1 & 0 & 1 \\
\hline 1 & 0 & 1 \\
\hline-1 & 0 & 1 \\
\hline
\end{tabular}

mengoptimalkan rasio signal-to-noise dan lokalisasi area. Operator Canny merupakan turunan pertama dari fungsi Gaussian. Citra yang telah diperhalus dinyatakan $\mathrm{I}[\mathrm{i}, \mathrm{j}]$ dan $\mathrm{G}[\mathrm{i}, \mathrm{j}, \sigma]$ adalah notasi untuk filter Gaussian dengan $\sigma$ merupakan faktor Gaussian dan pengontrol derajat kehalusan suatu citra.

$$
G(x, y)=\frac{1}{\sqrt{2 \pi \sigma}} e^{-\frac{x^{2}+y^{2}}{2 \sigma^{2}}}
$$

Hasil dari konvolusi I $[\mathrm{i}, \mathrm{j}]$ dengan $\mathrm{G}[\mathrm{i}, \mathrm{j}, \sigma]$ adalah

$$
S[i, j]=G[i, j, \sigma]^{*} I[i, j]
$$

Untuk menghitung magnitude gradient dibutuhkan komponen $\mathrm{x}$ dan y yang dapat dicari dengan turunan parsial dari $\mathrm{P}[\mathrm{i}, \mathrm{j}]$ dan $\mathrm{Q}[\mathrm{i}, \mathrm{j}]$.

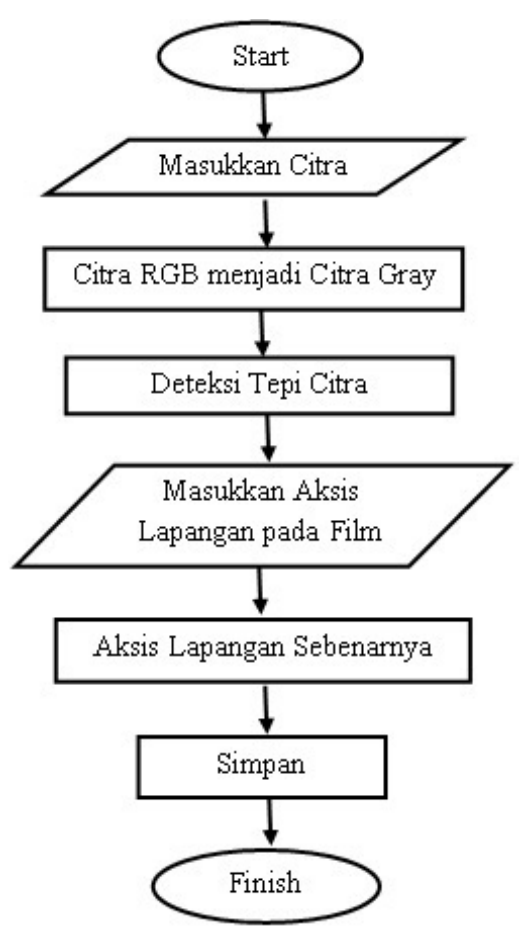

Gambar 2: Flowchart Program.

$$
\begin{array}{r}
P[i, j] \approx \\
Q[i, j] \approx \frac{S[i, j]-S[i+1, j]+S[i, j+1]-S[i+1, j+1]}{2}
\end{array}
$$

Magnitude gradien dinyatakan dalam [4]:

$$
M[i, j]=\sqrt{P[i, j]^{2}+Q[i, j]^{2}}
$$

\section{Diagram Alir}

Diagram alir penelitian ini ditunjukkan pada Gambar 2.

\section{HASIL DAN PEMBAHASAN}

Citra simulator nampak jelas jika dideteksi tepinya menggunakan metode Canny. Citra nampak seperti citra asli yang tepinya lebih tajam. Apabila dibandingkan dengan metode LoG dan metode Zero Cross, metode canny lebih bersih dari noise seperti pada Gambar 3(a). Noise merupakan efek pencahayaan yang ditangkap oleh film sehingga terdeteksi oleh formula. Metode canny digunakan pada citra yang memiliki tepi curam. Citra simulator merupakan citra yang memiliki tepi curam, sehingga metode deteksi canny yang cocok digunakan untuk mendeteksi tepi karena noise citra asli tidak terbaca. Hasil metode Canny paling rapi dibanding dengan metode yang lainnya.

Metode Canny memiliki output yang halus dan obyekobyek yang tidak diinginkan dapat direduksi [5]. Penggunaan metode Canny memiliki efiensi algoritma dan kompleksitas yang tinggi akan tetapi citra yang dihasilkan akurat [6]. Tampilan program ditunjukkan pada Gambar 4.

Dalam tampilan tersebut terdapat tombol-tombol untuk menampilkan citra asli, citra olah dan citra hasil. Panel perhitungan luas lapangan berisi masukan-masukan yang diperlukan dalam proses perhitungan. Program mudah dijalankan, karena ada menu informasi pada menu editor yang berisi petunjuk penggunaan program. Pada saat pemanggilan, citra asli harus dalam format *.jpg oleh karena citra film harus 


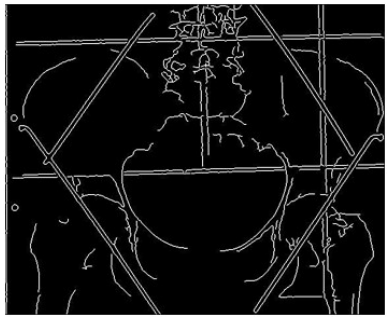

(a) Canny

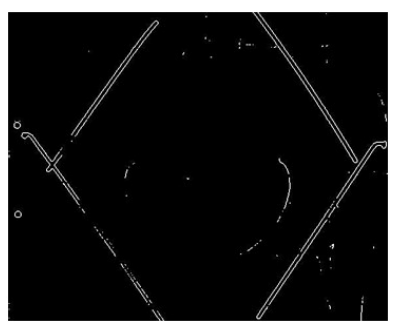

(c) Prewitt

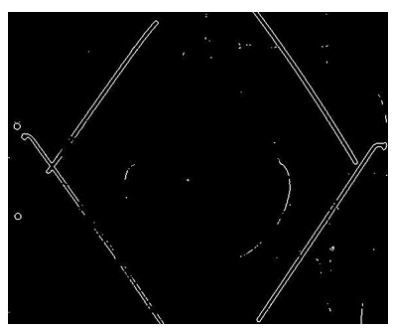

(e) Sobel

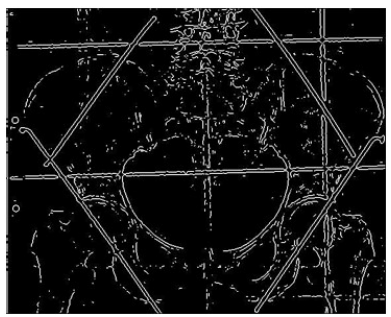

(b) LoG

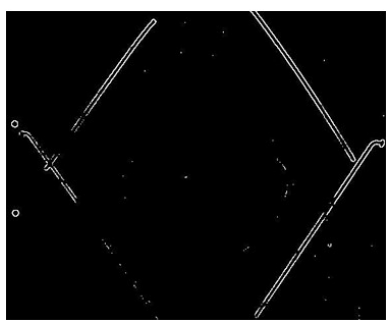

(d) Roberts

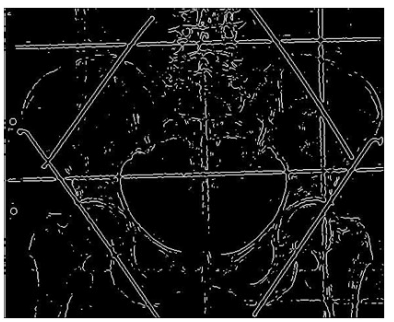

(f) Zero Cross
Gambar 3: Citra Hasil Deteksi Tepi.

didigitalisasi dengan discan terlebih dahulu. Citra tersebut bertipe RGB maka diubah menjadi tipe Gray supaya mempersingkat proses deteksi tepi.

Program juga diberikan fasilitas untuk mengubah arah citra yakni dengan tombol rotasi ke kanan atau ke kiri. Pengguna diberi kemudahan untuk memilih hasil deteksi tepi dari masing-masing metode tanpa harus mengulangi proses awal. Citra yang dipilih tersebut ditampilkan pada panel citra filter. Citra yang terpilih dapat disimpan dengan cara mengklik tombol simpan, maka citra akan disimpan dalam format *.jpg dalam file direktori MATLAB.

Pada film terbentuk blok aksis penyinaran yang mana blok tersebut sudah terpasang pada pesawat simulator. Blok tersebut tercetak pada film dan dapat diukur dengan mistar. Pengukuran aksis penyinaran pada film ditampilkan pada Tabel 7. Aksis penyinaran yang terbentuk sebagai mapping dan verifikasi lapangan penyinaran. Untuk mendapatkan aksis penyinaran pada obyek sebenarnya dihitung dengan Pers.(2) dan Pers.(3) sehingga menghasilkan luasan pada Tabel 8.

Magnifikasi menunjukkan perbandingan luasan blok penyinaran pada keadaan sebenaranya dengan luasan blok penyinaran pada film. Hubungan $\mathrm{M}$ dan $\mathrm{D}_{2}$ berbanding lurus, sehingga semakin jauh obyek dengan film, nilai magnifikasi akan semakin besar.

TABEL VII: Mapping Film.

\begin{tabular}{lccccc}
\hline \hline Sampel & $\begin{array}{c}\mathrm{D}_{2} \\
(\mathrm{kali})\end{array}$ & $\begin{array}{c}\mathrm{X}+ \\
(\mathrm{mm})\end{array}$ & $\begin{array}{c}\mathrm{X}- \\
(\mathrm{mm})\end{array}$ & $\begin{array}{c}\mathrm{Y}+ \\
(\mathrm{mm})\end{array}$ & $\begin{array}{c}\mathrm{Y}- \\
(\mathrm{mm})\end{array}$ \\
\hline S1 & 40 & 75 & 75 & 80 & 80 \\
S2 & 37,5 & 78 & 78 & 80 & 80 \\
S3 & 40 & 75 & 75 & 82 & 82 \\
S4 & 45 & 70 & 70 & 65 & 65 \\
S5 & 45 & 85 & 85 & 85 & 85 \\
\hline
\end{tabular}

TABEL VIII: Mapping Film.

\begin{tabular}{lccccc}
\hline \hline Sampel & $\begin{array}{c}\mathrm{M} \\
(\mathrm{kali})\end{array}$ & $\begin{array}{c}\mathrm{X}+ \\
(\mathrm{mm})\end{array}$ & $\begin{array}{c}\mathrm{X}- \\
(\mathrm{mm})\end{array}$ & $\begin{array}{c}\mathrm{Y}+ \\
(\mathrm{mm})\end{array}$ & $\begin{array}{c}\text { Y- } \\
(\mathrm{mm})\end{array}$ \\
\hline S1 & 1,5 & 50 & 50 & 53,3 & 53,3 \\
S2 & 1,47 & 53,1 & 53,1 & 54,4 & 54,4 \\
S3 & 1,5 & 50 & 50 & 54,6 & 54,6 \\
S4 & 1,56 & 44,8 & 44,8 & 41,6 & 41,6 \\
S5 & 1,56 & 54,4 & 54,4 & $54,454,4$ & \\
\hline \hline
\end{tabular}

\section{SIMPULAN}

Untuk citra sinar X, metode yang paling tepat untuk mendeteksi tepi adalah metode Canny. Karakter citra sinar X memiliki tepi curam dan memiliki noise, akan tetapi noise tersebut dapat direduksi dengan filter Gaussian, sehingga hasil deteksi tepinya hanya mendeskripsikan obyek citra dan hasil mendekati citra asli. Selain itu blok aksis penyinaran nampak lebih jelas batasnya. Program untuk mendeteksi tepi citra dan menghitung aksis lapangan penyinaran dapat dibuat dalam software MATLAB.
[1] R. Sjahriar, S. Kartoleksono, and I. Ekayuda, Radiologi Diagnostik (FK UI, Jakarta, 2001).

[2] R.H. Sianipar, H.S. Mangiri, and I.K. Wiryajadi, MATLAB untuk Pemrosesan Citra Digital (Informatika, Bandung, 2013).

[3] D. Putra, Pengolahan Citra Digital (Andi Offset Yogyakarta, 2010).

[4] G.T. Shrivaskshan, and C. Chandrasekar, International Journal of
Computer Science Issues, 9(1), 269-276 (2012).

[5] A. Mousa, International Journal of Signal Processing, Image Processing and Pattern Recognition, 5(3), 1-7 (2012).

[6] S.K. Mahendran, International Journal of Engineering and Innovative Techonology, 2(5), 190-193 (2012). 


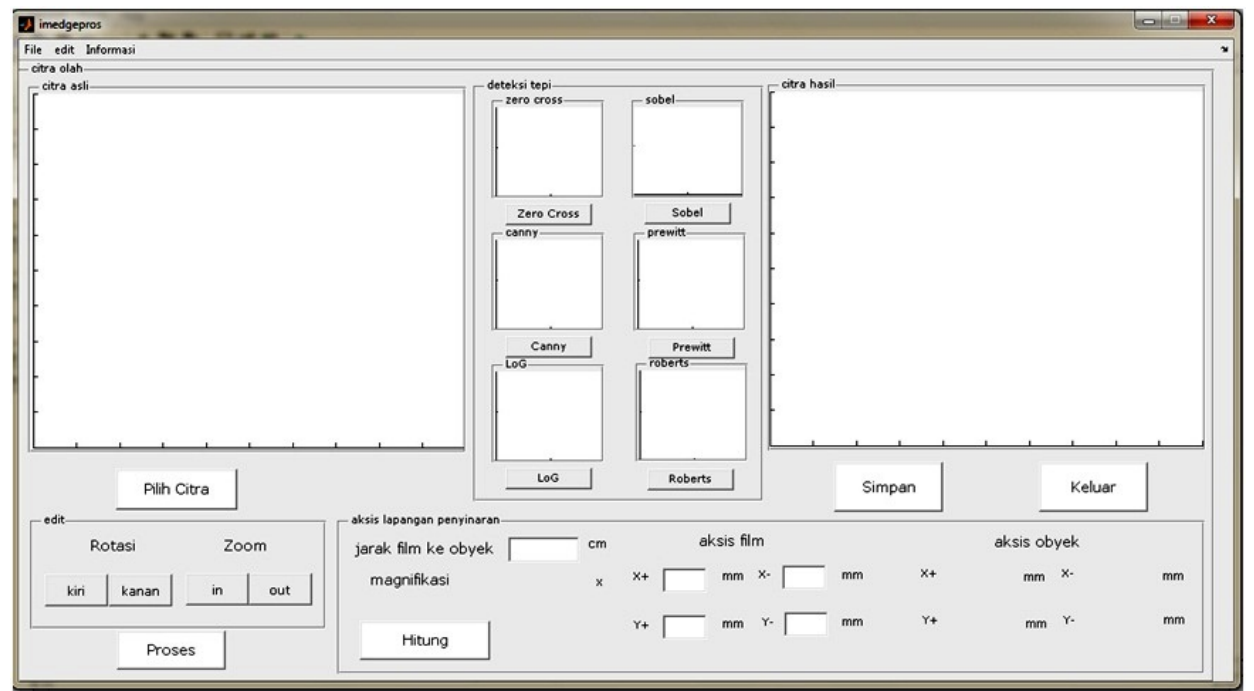

Gambar 4: Tampilan Program. 